VIEIRA, José Rodolfo. Footnotes in Gaza: representações sobre o Hamas durante as eleições na Palestina por meio das histórias em quadrinhos de Joe Sacco. Domínios da imagem, v. 13, n. 24, p. 157-186, jan./jun. 2019.

Recebido em 1/9/2019 e aprovado em 16/11/2019

\title{
FOOTNOTES IN GAZA: REPRESENTAÇÕES SOBRE O HAMAS DURANTE AS ELEIÇÕES NA PALESTINA POR MEIO DAS HISTÓRIAS EM QUADRINHOS DE JOE SACCO (2002-2010)
}

\section{FOOTNOTES IN GAZA: REPRESENTATIONS ON HAMAS DURING THE ELECTIONS IN PALESTINE THROUGH JOE SACCO'S COMICS (2002- 2010)}

José Rodolfo Vieira

Resumo: $O$ objetivo deste trabalho consiste em compreender as mais variadas formas de representações acerca às eleições do corpo legislativo na Palestina em janeiro de 2006, nas páginas de Notas sobre Gaza do jornalista estadunidense Joe Sacco. Inserida no macro evento da guerra contra o terrorismo, iniciado após os ataques às Torres Gêmeas em setembro de 2001 nos Estados Unidos, as eleições na Palestina foram vencidas pelo grupo militar Hamas, reconhecido como grupo terrorista na Europa, por Israel e Estados Unidos. Em nossa tentativa de analisar as representações acerca dessas eleições, observaremos, além de "Notas sobre Gaza" escolhida como nossa fonte, documentos emitidos pelas Nações Unidas e de periódicos estadunidenses como o The New York Times e The Washington Post. Diante desse escopo de fontes documentais, questionaremos como esses grupos, aqueles que produzem os sistemas de representações e que consequentemente disputam entre si a sua representação do mundo como sendo a "real", a grande "verdade" criada e estabelecida conforme suas necessidades e seus interesses acerca das eleições na Palestina e especialmente sobre o papel do Hamas nessas eleições. Como metodologia, utilizaremos os preceitos de Jean Starobinsky acerca da análise dos textos literários. Como referencial teórico, nosso estudo será embasado pelo conceito de representações do historiador francês Roger Chartier. Por fim, compreendemos a disparidade existente nas representações entre os meios de comunicação estadunidenses e as representações contidas em "Notas sobre Gaza", especialmente acerca dos acontecimentos que permeiam o processo de sua produção.

Palavras-Chave: Hamas; Faixa de Gaza; Meios de comunicação.

\footnotetext{
- Mestre em História Social pela Universidade Estadual de Londrina (UEL) PR, em 2017, doutorando em História e Sociedade pela Universidade Estadual Paulista - Júlio de Mesquita Filho (UNESP) SP, graduado em licenciatura em História pela Universidade Estadual de Londrina (UEL) PR, em 2015. Essa pesquisa foi realizada graças ao apoio financeira da Coordenação de Aperfeiçoamento de Pessoal de Nível Superior (CAPES). E-mail: rodolfohistoriavel@gmail.com.
} 
VIEIRA, José Rodolfo. Footnotes in Gaza: representações sobre o Hamas durante as eleições na Palestina por meio das histórias em quadrinhos de Joe Sacco. Domínios da imagem, v. 13, n. 24, p. 157-186, jan./jun. 2019.

Abstract: The purpose of this paper is to understand the most varied forms of representations about the elections of the legislative body in Palestine in January 2006, in the pages of "Notes on Gaza" of the American journalist Joe Sacco. Inserted in the macro-event of the war on terror, started after the attacks on the Twin Towers in September 2001 in the United States, elections in Palestine were won by the Hamas military group, recognized as a terrorist group in Europe, by Israel and the United States. In our attempt to analyze the representations about these elections, we will observe, in addition to "Notes on Gaza" chosen as our source the object of research, documents issued by the United Nations and American periodicals such as The New York Times and The Washington Post. Faced with this scope of documentary sources, we will question how these groups, producers of systems of representations that dispute among themselves the representation of their truth created and established according to their needs and their interests about the elections in Palestine and especially about the role of Hamas in these elections. As a methodology, we will use the precepts of Jean Starobinsky about the analysis of literary texts. As a theoretical reference, our study will be based on the concept of representations of the French historian Roger Chartier. Finally, we understand the disparity in representations between the US media and the representations contained in "Notes on Gaza", especially about the events that permeate the process of their production.

Key-Words: Hamas; Gaza Strip; Media.

\section{Introdução}

Os resultados apresentados neste artigo são referentes a um trabalho muito maior desenvolvido em minha tese de doutoramento. Nesse trabalho, que vem sendo desenvolvido há cerca de dois anos, tento trazer luz a compreensão de "Notas sobre Gaza" como fonte e objeto de pesquisa. Notas sobre Gaza representa dois massacres específicos que aconteceram na Faixa de Gaza, um em Khan Younis e o outro em Rafah, durante a Guerra de Suez, de 1956, travada entre Israel, França e Inglaterra contra o Egito e que levou a morte mais de duzentos e cinquenta palestinos. Durante o litígio entre essas forças beligerantes, o incipiente grupo militar palestino, denominado de fedayeen que lutou ao lado do Egito, se apresentou como força de resistência palestina na região. Inserido nesse macro acontecimento (Guerra de Suez), os dois massacres às aldeias de Gaza podem ser observados como micro 
VIEIRA, José Rodolfo. Footnotes in Gaza: representações sobre o Hamas durante as eleições na Palestina por meio das histórias em quadrinhos de Joe Sacco. Domínios da imagem, v. 13, n. 24, p. 157-186, jan./jun. 2019.

acontecimentos, visto que parecem ser um modesto episódio diante da repercussão causada pelo conflito em Suez.

Portanto, ao considerarmos "Notas sobre Gaza" como fonte e objeto de estudo, é de suma importância compreendermos os elementos internos e externos que convergem em seu processo de produção. Esse conjunto de representações foi produzido pelo jornalista estadunidense Joe Sacco entre 2002 e 2010. Joe Sacco é um jornalista radicado nos Estados Unidos, mas de origem maltesa. Ainda muito jovem, ele foi morar nos Estados Unidos onde cursou jornalismo pela Universidade do Óregon, na década de 1980. Após findar seus estudos, passou a fazer parte da editora de quadrinhos alternativos Fantagraphic Books. Além do papel de editor, Sacco publicou Yahoo!, seu primeiro trabalho autoral que descrevia suas desilusões como jornalista e outras histórias pessoais, que apresentou vendagem muito pequena, cerca de 6 mil exemplares, para o estilo alternativo de Histórias em Quadrinhos (esperava-se cerca de 20 mil unidades vendidas) (BARKER, 2012). No final da década de 1980, Sacco viaja para Europa onde acompanha bandas de rock em suas turnês, ganhando a vida ilustrando cartazes de bandas para suas apresentações. No entanto, com o advento da década de 1990, eclode na Palestina a Primeira Intifada (1987-1993)' '. Por razões pessoais se interessa pela crise no Oriente Médio e resolve, por conta própria e com poucos recursos financeiros, fazer a cobertura dos eventos que se desenrolavam na Faixa de Gaza e na Cisjordânia. O resultado dessa viagem foi a publicação de Palestine. Sobre Palestine, o autor afirma que:

\footnotetext{
1 A Primeira Intifada na Palestina tem seu início em dezembro de 1897. Após a morte de uma família palestina em um acidente de carro que envolvia um caminhão israelense, os palestinos passaram a revidar com severidade as Forças de Defesa de Israel. A Intifada tem como sua maior característica a participação popular que durante esse período passou a jogar pedras contra os soldados e jipes israelenses. Ainda durante a Intifada surge o grupo fundamentalista Hamas em contradição ao Fatah e a lisura no qual Yasser Arafat negociava o Acordo de Oslo de 1993 (GATTAZ, 2003).
} 
VIEIRA, José Rodolfo. Footnotes in Gaza: representações sobre o Hamas durante as eleições na Palestina por meio das histórias em quadrinhos de Joe Sacco. Domínios da imagem, v. 13, n. 24, p. 157-186, jan./jun. 2019.

É frequente me perguntarem por que resolvi meter o nariz no conflito entre Israel e Palestina. Na verdade, respondi tantas vezes a esta pergunta que eu mesmo já considero minha resposta insossa, mas vou repeti-la, pois é verdade: Fui ao território Ocupado porque senti que era a minha obrigação. Quer dizer, quando comecei a compreender a opressão a que eram sujeitos os palestinos, fui tomado de uma quase biológica necessidade de agir (SACCO, 201 1, p. xvi).

Essa necessidade quase "biológica" descrita pelo autor faz referência a sua formação jornalística. Sendo graduado em jornalismo e consequentemente alguém que conhece os métodos de produção e veiculação de informações, Sacco afirma que a maneira cujas notícias eram produzidas pelos meios de comunicação estadunidenses deixavam a desejar. Em sua visão de mundo, os fatos sempre eram discorridos a partir do ponto de vista israelense. É por meio desse ponto de vista que tanto "Palestine" como "Notas sobre Gaza" são produzidos. Apesar dos mais de vinte anos que separam um do outro, a explicação descrita pelo autor é legitimada pela discrepância na maneira de como as pessoas, especialmente os estadunidenses, são informados e informam o mundo, por meio dos grandes meios de comunicação, tais como o The New York Times e o The Washington Post, ambos analisados neste trabalho, acerca dos acontecimentos que permeiam o conflito entre Israel e Palestina.

Além desse fator biológico, que o conduz a buscar um contrapeso nas representações do conflito, a viagem com o jornalista Chris Hedge, em 2001, para a produção de um material para a revista Harper's foi fundamental para o início de uma nova empreitada na Palestina. Segundo Sacco (2010, p.xvi) "A gênese desse livro remonta ao primeiro semestre de 2001, quando eu e o jornalista Chris Hedges nos preparávamos para ir à Faixa de Gaza como enviados especiais da revista Harper's". Ainda conforme Sacco, um trecho desse material produzido em conjunto com Hedge havia sido cortado pelo editor. O trecho retirado do material original continha o relato de El-Rantisi sobre os dois massacres em Gaza na década de 1950. Foi diante dessa história 
VIEIRA, José Rodolfo. Footnotes in Gaza: representações sobre o Hamas durante as eleições na Palestina por meio das histórias em quadrinhos de Joe Sacco. Domínios da imagem, v. 13, n. 24, p. 157-186, jan./jun. 2019.

não contada pela revista Harper's que encontramos outro motivo para Sacco retornar à Palestina e dar andamento ao seu segundo trabalho nos territórios ocupados por Israel.

Aqui se faz necessário apresentar como os trabalhos de Sacco se situam no universo de produção das Histórias em Quadrinhos. Após um grande perío do de campanhas contra os quadrinhos nos Estados Unidos em meados da década de 1940, o projeto de criminalizar os quadrinhos encabeçado pelo pesquisador e psiquiatra Friedric Werthan, tentava esclarecer como os quadrinhos poderiam influenciar de maneira negativa a juventude estadunidense, especialmente os elementos que ele considerava como sendo violentos. Essa campanha chegou ao Senado que aprovou em 1954 a formação do Comics Magazine Association of America (GARCIA, 2012, p. 156). Mais conhecida como Comic Code, essa associação impunha rígidas restrições para a produção de quadrinhos, pois para a publicação e a distribuição de quadrinhos, era necessário o selo de garantia da Comic Code. Santiago Garcia (2012)afirma que o resultado para a indústria dos quadrinhos após as imposições do Comic Code foi desastroso, pois levou a queda de quase 50\% nas vendas entre 1954 e 1955.

Mesmo com as restrições e a vigilância impostas pelo Comic Code, surge um movimento contracultural nos quadrinhos na década de 1960. Concomitante com a produção de Barbarella de Jean Claude-Forest, que já trazia elementos femininos e sexualizados para os quadrinhos na França de 1968. Nos Estados Unidos essa mudança ficou a cargo de Robert Crumb e o lançamento de sua revista underground "Zap Comix" (MAZUR; DANNER, 2014, p. 9). Com desenhos mais tracejados e com temáticas que variavam entre a sexualidade e as drogas, o movimento underground nos Estados Unidos foi uma manifestação contra as imposições restritivas do Comic Code e favorável a liberdade de poder produzir quadrinhos fora do campo dos quadrinhos mainstream, ou seja, das grandes editoras e dos roteiros de super-heróis. Para Garcia (2012, p. 164), o underground pode ser considerado um grande 
VIEIRA, José Rodolfo. Footnotes in Gaza: representações sobre o Hamas durante as eleições na Palestina por meio das histórias em quadrinhos de Joe Sacco. Domínios da imagem, v. 13, n. 24, p. 157-186, jan./jun. 2019.

movimento de ruptura, visto que além das temáticas atuais que trazia em seus roteiros (sexo, drogas e rock'n roll) dos anos de 1960 e 1970, os quadrinhos desenhados por Crumb também carregavam elementos do passado, como as referências do estilo big-foot, muito utilizado pelos estúdios Disney.

Com o fim do inicial impulso criativo do movimento underground em meados da década de 1970, um novo grupo de quadrinistas começa a ganhar espaço dentro do campo das HQ's. Dissidentes do movimento underground, quadrinistas como Spielgeman e Bill Griffin passam a publicar novos títulos de revistas em quadrinhos como a "Arcade" e a "Raw". O intuito desses dissidentes era realizar uma [re]leitura do movimento underground, mas com alterações no escopo de temáticas. A partir de então os elementos que remetiam as drogas e ao sexo vão dando lugar as narrativas de não-ficção (MAZUR; DANNER, 2014, p. 41). O grande marco dessa geração que será conhecida como alternativos foi a produção de "Maus", por Spielgeman em meados da década de 1980. Nesse trabalho, Spielgeman narra a história de seu pai, Vladek Spielgeman e sua experiência como sobrevivente de Auschwitz e levou Spielgeman a ganhar um prêmio Pulitzer.

$\mathrm{Na}$ esteira dos quadrinhos de não-ficção é que Sacco viaja para Palestina com a intenção de produzir suas narrativas quadrinísticas. Tal como em sua primeira viagem aos territórios ocupados (1991-1992), acontecia na Palestina uma nova Intifada, essa iniciada em 2000, motivada principalmente pelos fracassos dos Acordos de Oslo em 1993, que por parte dos palestinos havia o descontentamento com as concessões realizadas com Israel que acreditavam estar favorecendo muito mais aos israelenses. Outro fator determinante para o início dessa nova Intifada foi a impotência da Organização pela Libertação da Palestina (OLP), liderada pelo Fatah e pelo icônico líder palestino Yasser Arafat de conduzir uma negociação que se prestasse favorável a causa palestina em Oslo (GATTAZ, 2003, p. 191). Apesar dos alvos estadunidenses terem sido voltados para o Afeganistão e o Iraque, a Palestina não ficou de fora da rota de colisão dessa guerra. Segundo dados 
VIEIRA, José Rodolfo. Footnotes in Gaza: representações sobre o Hamas durante as eleições na Palestina por meio das histórias em quadrinhos de Joe Sacco. Domínios da imagem, v. 13, n. 24, p. 157-186, jan./jun. 2019.

coletados pela Uppsala University (2019), a escalada da violência pós 2001 na Palestina cresceu vertiginosamente, ainda mais se comparada com os dados da década que precede os ataques às Torres Gêmeas. Conforme os dados levantados, entre 2001 e 2010, houve 5165 mortos na região, em contraste com a década anterior (1991-2000) que registrou 673 mortes com armas de fogo na região. Ou seja, conforme esses dados, podemos observar que com o início da guerra contra o terrorismo, iniciada em 2002 pelos Estados Unidos e seus aliados, ocorreu uma grande escalada de violência na região. Uma das prováveis explicações sobre esse aumento no número de mortos na região é a relação entre Estados Unidos e Israel na guerra contra o terrorismo. Sobre a relação entre Israel e Estados Unidos, Bernard Lewis discorre:

Durante muito tempo, esse relacionamento foi moldado por duas considerações inteiramente diferentes: uma delas pode ser chamada ideológica ou sentimental; a outra, estratégica. Os norte-americanos, escolados na Bíblia e em sua própria história, podem prontamente ver o nascimento do moderno Estado de Israel como um novo Êxodo e um retorno à Terra Prometida, e acham fácil desenvolver uma empatia por pessoas que parecem estar repetindo a experiência dos peregrinos fundadores, dos pioneiros e dos que os sucederam. Os árabes, por certo, não veem dessa maneira, e muitos europeus também não. O outro vínculo entre os Estados Unidos e Israel é a relação estratégica, que começou na década de 1960, floresceu nas décadas de 1970 e 1980, flutuou nos anos 90 e ganhou nova importância quando os Estados Unidos enfrentaram as atuais ameaças das ambições hegemônicas de Saddam Husseim, do terror fundamentalista da Al'Qaeda e de profundos e crescentes descontentamentos entre os aliados árabes da América (LEWIS, 2004, p. 99).

Dessa maneira, a relação entre Israel e Estados Unidos parece ser muito bem entrelaçada, tanto no quesito ideológico como também na esfera estratégica. Diante dessa relação entre Estados Unidos e Israel, a escalada da violência observada nos dados apontados pela Uppsala não deve ser averiguada como mera coincidência, pois ao mesmo tempo que os Estados Unidos iniciam sua cruzada contra os terroristas no Oriente Médio, Israel dá início a um forte processo de repressão na Palestina. Assim sendo, ambos os 
VIEIRA, José Rodolfo. Footnotes in Gaza: representações sobre o Hamas durante as eleições na Palestina por meio das histórias em quadrinhos de Joe Sacco. Domínios da imagem, v. 13, n. 24, p. 157-186, jan./jun. 2019.

acontecimentos devem ser analisados como acontecimentos que se relacionam pelo mesmo objetivo em comum, ou seja, a "nova" política externa estadunidense.

Para compreender essa "nova" política externa americana, devemos voltar nossa atenção ao final do período conhecido como Guerra Fria. Para o historiador britânico Perry Anderson, mesmo após o fim do período conflituoso e beligerante da Guerra Fria, no qual os Estados Unidos se deram como vencedores contra o comunismo soviético, os perigos adversos a democracia e a liberdade não tinham findado.

Nem todos os perigos à liberdade, no entanto, haviam sido
afastados. Em 2001 os terroristas que atacaram as Torres
Gêmeas e o Péntagono, assim como os japoneses que
bombardearam Pearl Harbor, haviam 'dado aos EUA mais uma
oportunidade de liderar o mundo em direção a uma nova era'
e George W. Bush - o subestimado Príncipe Hal da hora -
encontrava forças para o desafio de criar um 'império de
liberdade' ao se manter à altura da vocação do país como, nas
palavras de Lincoln, 'a última e melhor esperança da
humanidade' (ANDERSON, 2015, p. 47).

Assim sendo, conforme Anderson, os ataques contra as Torres Gêmeas impulsionaram os Estados Unidos a tomarem a dianteira para formação de um Império de Liberdade que se fazia necessário contra uma nova ameaça mundial, ou seja, o terrorismo fundamentalista islâmico. Esse foi um campo fértil para a guinada do grupo de intelectuais neoconservadores nos Estados Unidos. Francis Fukuyama, muito conhecido pelo seu famoso livro $O$ fim da História, se considerava como neoconservador até meados da década de 2000. No entanto, no decorrer dos acontecimentos que levaram os Estados Unidos as guerras contra o Afeganistão e o Iraque, diz ter se arrependido. Em O dilema americano, além de fazer essa confissão, Fukuyama explica para seus interlocutores quem são os neoconservadores e quais os pontos de sua agenda de política externa: 
VIEIRA, José Rodolfo. Footnotes in Gaza: representações sobre o Hamas durante as eleições na Palestina por meio das histórias em quadrinhos de Joe Sacco. Domínios da imagem, v. 13, n. 24, p. 157-186, jan./jun. 2019.

Os intelectuais neoconservadores, nos seus anos fora do poder, antes da eleição de 2000, haviam proposto uma agenda para a política externa que envolvia conceitos como mudança de regime, hegemonia benevolente, unipolaridade, preempção e a excepcionalidade americana, os quais passaram a ser as marcas da política externa do governo Bush. Muitos neoconservadores eram fortes defensores públicos da guerra e patrocinavam a mudança de foco do al-Qaeda para o Iraque. (FUKUYAMA, 2006, p. 16-17)

O resultado dessa agenda é denominado por Fukuyama como "Doutrina Bush". O intento dessa agenda era colocar os Estados Unidos em um lugar de destaque nas relações internacionais e retomar o seu lugar de líder mundial que deveria levar a liberdade e a democracia para os lugares mais incultos. Para que essa agenda tivesse sucesso, dois elementos seriam importantes para sua legitimação; o patriotismo exacerbado após o 11 de setembro e o discurso midiático acerca do mundo muçulmano. Sobre o patriotismo exacerbado que emergiu entre os estadunidenses após a queda das Torres Gêmeas Jan Nederveen Pieterse, professor holandês que vivia nos Estados Unidos, relata que:

Durante ao menos um ano após o 11 de Setembro, o ar ficou cheio de patriotismo, prevalecendo uma febre exibição da bandeira, total deferência da mídia e uma cultura da obediência. Durante cerca de um ano, se eu andasse por duas quadras do meu bairro suburbano contaria mais umas cem bandeiras americanas na frente das casas, nas janelas ou nos adesivos de carro [...] Aos poucos, a normalidade voltou, a mídia recolocou os pés no chão, embora evitando posturas críticas (velha normalidade), e o comportamento do público ficou mais contido (NEDERVEEN PIETERSE, 2009, p. 56).

O culto a bandeira e a outros elementos simbólicos que idolatravam e identificavam a cultura estadunidense floresceram nos bairros suburbanos nos Estados Unidos. Susan Willis também destaca os atos de patriotismo pelos estadunidenses após os ataques ao World Trade Center. 
VIEIRA, José Rodolfo. Footnotes in Gaza: representações sobre o Hamas durante as eleições na Palestina por meio das histórias em quadrinhos de Joe Sacco. Domínios da imagem, v. 13, n. 24, p. 157-186, jan./jun. 2019.

Imediatamente após os ataques ao World Trade Center, os Estados Unidos responderam com o rápido desfraldar da bandeira norte-americana. A ânsia por exibi-la inflamou-se graças à fotografia de três bombeiros que a hastearam - no estilo da famosa imagem produzida em Iwo Jima - sobre os escombros no sul de Manhattan; essa foto seria exibida nas páginas dos jornais de todo o país. O desejo de perpetuar a heroica imagem levou a companhia de desenvolvimento Forest City Ratner a encomendar uma estátua, feita a partir da fotografia, que será colocada na sede do corpo de bombeiros da cidade de Nova York (WILLIS, 2008, p. 17)

Concomitante ao patriotismo estadunidense diante da enormidade do desastre e o custo humano, além do trauma que os ataques causaram, o segundo elemento que contribui para nossa análise é o fenômeno midiático que pairava pelos Estados Unidos após os ataques de setembro de 2001. Segundo Noam Chomsky (2013, p.23), as relações públicas nos Estados Unidos "representam um vasto campo de atividade. Elas gastam hoje em torno de 1 bilhão de dólares por ano. Durante todo esse tempo, seu compromisso foi controlar a mente da população". Diante dessas circunstâncias, tanto o forte patriotismo exacerbado após a queda das torres quanto o forte investimento em relações públicas, especialmente nas comunicações midiáticas, foram elementos catalisadores para a disseminação do medo irracional entre os estadunidenses. Conforme Eric Hobsbawm:

É compreensível que esses movimentos criem grande nervosismo entre as pessoas comuns, sobretudo nas metrópoles do Ocidente e especialmente quando os governos e a imprensa se empenham em gerar um clima de medo, para alcançar seus próprios propósitos, e dão publicidade máxima às ações. (É difícil lembrar que antes de 2001 a atitude padrão, inteiramente racional, dos governos diante desses movimentos - ETA, Brigadas Vermelhas, IRA - visava 'negar-lhes o oxigênio da publicidade' tanto quanto possível) Trata-se de um clima de medo irracional. A política atual dos Estados Unidos tenta reviver os terrores apocalípticos da Guerra Fria, quando já não Ihe é plausível inventar 'inimigos para legitimar sua expansão e o emprego do seu poder global. Repito aqui que os perigos da 'guerra ao terror' não provêm dos homens-bomba muçulmanos (HOBSBAWM, 2007, p. 136). 
VIEIRA, José Rodolfo. Footnotes in Gaza: representações sobre o Hamas durante as eleições na Palestina por meio das histórias em quadrinhos de Joe Sacco. Domínios da imagem, v. 13, n. 24, p. 157-186, jan./jun. 2019.

Portanto, as bases para a construção de um novo inimigo foram estruturadas nos Estados Unidos. O inimigo que os neoconservadores esperavam surgir para que a agenda de política externa que eles almejavam colocar os Estados Unidos como líder mundial foi encaixada aos muçulmanos após os ataques ao World Trade Center em 2001. É a partir desse quadro histórico que levantamos a hipótese para este trabalho. Portanto, se 011 de setembro surgiu como uma grande oportunidade para os neoconservadores colocarem em prática sua agenda - utilizando o medo irracional por meio dos meios de comunicação - , e, concomitante a isso Sacco retorna à Palestina com o intuito de produzir um novo material sobre a ocupação israelense, não seria então as representações dos massacres das aldeias na Faixa de Gaza em 1956 uma crítica implícita da política externa estadunidense contida em Notas sobre Gaza?

Com o intuito de resolver esse problema, selecionamos então "Notas sobre Gaza" como nossa fonte e objeto de pesquisa. Para isso, recortamos neste estudo o período que consiste as eleições do corpo legislativo palestino em janeiro de 2006 e a atuação dos meios de comunicação dos Estados Unidos em contraste com as representações de Joe Sacco. Para que possamos resolver esse problema, utilizaremos como aporte metodológico a análise de Jean Starobinski para os estudos de obras literárias. Segundo Starobinski:

Se partirmos para os projetos mais antigos, perceber-se-á como a obra, em seu começo, opõe-se e combina-se com textos antecedentes, assimila e transforma livros precursores: a sua originalidade, a sua individualidade destacam-se contra um fundo constituído pela massa coletiva de recursos de linguagem, das formas literárias recebidas, das crenças, dos conhecimentos, que ela reativa, critica, e ao qual se acrescenta. São outras tantas camadas e acidentes de terreno (com fontes, afluentes, elevações), em que a obra escolhe o seu local e sua vizinhança (STAROBINSKI, 1976, p. 134) 
VIEIRA, José Rodolfo. Footnotes in Gaza: representações sobre o Hamas durante as eleições na Palestina por meio das histórias em quadrinhos de Joe Sacco. Domínios da imagem, v. 13, n. 24, p. 157-186, jan./jun. 2019.

Tornar-se deveras importante salientar que o fato de utilizarmos os preceitos metodológicos de Starobinski para trabalhos literários consiste no fato de Notas sobre Gaza ser e publicado em formato de livro. Por isso, é significativo compreender e verificar os outros elementos que estão relacionados com a sua produção, por exemplo, as próprias notícias de periódicos e documentos oficiais das Nações Unidas que serão fundamentais para o confrontamento de informações contidas em "Notas sobre Gaza". No entanto, ao utilizarmos esse método não excluiremos que outros aspectos sejam analisados, tais como os próprios elementos que constituem as Histórias em Quadrinhos. Muito pelo contrário, o que está proposto em nosso trabalho a fusão de elementos que permitem analisar tanto os fatores exteriores da obra de Sacco como também os elementos que compões seu discurso enquanto linguagem das Histórias em Quadrinhos. Acredito que a análise combinada desses elementos permita averiguar "Notas sobre Gaza" muito além de seu discurso, ao mesmo tempo que permitirá dialogar com o mundo que o rodeia.

Por fim, e não menos importante, o conceito de representação do historiador francês Roger Chartier faz-se necessário como pano de fundo teórico no qual a pesquisa está embasada, pois segundo Chartier:

As percepções do social não são de forma alguma discursos neutros: produzem estratégias e práticas (sociais, escolares, políticas) que tendem a impor uma autoridade à custa de outros, por elas menosprezados, a legitimar um projeto reformador ou a justificar, para os próprios indivíduos, as suas escolhas e condutas (CHARTIER, 1990, p. 17)

Sendo então as representações sociais discursos providos de interesses por parte daqueles que os produzem, consideraremos em nosso trabalho dois grupos distintos, que, por meio de seu sistema de representações tentam impor para sociedade a sua verdade em contraposição ao outro grupo, e consequentemente o seu sistema de representações. Não é construir uma relação entre um grupo dominante e outro dominado, mas sim de grupos que 
VIEIRA, José Rodolfo. Footnotes in Gaza: representações sobre o Hamas durante as eleições na Palestina por meio das histórias em quadrinhos de Joe Sacco. Domínios da imagem, v. 13, n. 24, p. 157-186, jan./jun. 2019.

constroem símbolos e elementos para disseminar seu ponto de vista sobre o outro. Nesse caso, há de um lado os meios de comunicação nos Estados Unidos, que colaboraram na construção do mundo muçulmano como o perigo iminente e o novo inimigo contra a liberdade a ser abatido, e do outro, representações como as de "Notas sobre Gaza" de Joe Sacco, que por meio de outros elementos simbólicos tentam representar outra verdade sobre o Oriente Médio.

Hamas: além do bem e do mal.

Em janeiro de 2006 acontecia na Palestina a eleição para o corpo legislativo após vários anos de poder concentrado nas mãos do Fatah e na Organização pela Libertação da Palestina (OLP). Apesar de ser um evento importante para as relações entre Israel e Palestina, pois, uma eleição na Palestina representaria o próprio poder da democracia no Oriente Médio, essas eleições acabaram por não ser tão bem recebidas por Israel, e especialmente pelos Estados Unidos. O motivo que levou o governo de Washington a possivelmente refutar as eleições antes mesmo delas iniciarem girava em torno da participação do Hamas nessas eleições. Mesmo com o financiamento por parte dos Estados Unidos para as candidaturas do Fatah, o Hamas acabou saindo vitorioso no pleito. Diante dessa conjuntura, observaremos nas próximas páginas como a participação do Hamas foi representada nos meios de comunicação estadunidenses, e, em contrapartida, como Sacco representou sua visão de mundo durante o processo eleitoral palestino de 2006.

Em várias oportunidades descritas pelos meios de comunicação, a negação por parte dos Estados Unidos em referência à participação do Hamas no processo eleitoral sempre foi enfatizada na narrativa. O argumento mais utilizado pelos meios de comunicação sugeria que o Hamas, grupo islâmico fundamentalista, não deveria participar do pleito por ter em seu 
VIEIRA, José Rodolfo. Footnotes in Gaza: representações sobre o Hamas durante as eleições na Palestina por meio das histórias em quadrinhos de Joe Sacco. Domínios da imagem, v. 13, n. 24, p. 157-186, jan./jun. 2019.

estatuto o fim do Estado de Israel e a luta armada como ferramentas políticas na Palestina. A questão da iminente participação do Hamas nas eleições já estava sendo discutida nas Nações Unidas, desde novembro de 2005:

O Conselho sublinhou a importância das próximas eleições para - Conselho Legislativo da Palestina enquanto elemento essencial para o progresso do processo de paz. O Conselho enfatizou que a violência e o terror são incompatíveis com os processos democráticos e exortou todas as facções, incluindo o Hamas, a renunciar à violência, reconhecer o direito de Israel de existir e desarmar-se. O Conselho instou Israel a facilitar os preparativos e a condução das eleições, inclusive na Jerusalém Oriental ocupada² (UNITED NATIONS, 2005).

Essa preocupação antecipada das Nações Unidas acerca da participação do Hamas nas eleições estendeu-se até as vésperas do processo eleitoral. A preocupação tornara-se tão grande que, em janeiro de 2006, a Carter Center, um instituto estadunidense para a colaboração do desenvolvimento da democracia, foi enviada para os territórios ocupados na Faixa de Gaza a fim de realizar levantamento prévio das condições que antecediam as eleições. Tal relatório, produzido pelo instituto estadunidense, teve seus resultados publicados nas Nações Unidas, apontando que as eleições seriam realizadas em um momento de difíceis circunstâncias para os palestinos, visto que em outubro de 2005 havia acontecido a retirada unilateral de Israel da Faixa de Gaza3. Em certo momento, o documento apresenta otimismo ao dizer que há a possibilidade de renovação política dentro da Palestina após sete anos da expiração do mandato do Fatah na região. No entanto, o tom otimista do relatório dá lugar a um tom mais sombrio ao apontar o que poderia ser considerado o maior problema para que as

\footnotetext{
2 [No original]: "The Council underlined the importance of the forthcoming elections for the Palestinian Legislative Council as an essential element for progress in the peace process. The Council emphasized that violence and terror are incompatible with democratic processes and urged all factions, including Hamas, to renounce violence, recognize Israel's right to exist, and disarm. The Council urged Israel to facilitate the preparations and conduct of the elections, including in occupied East Jerusalem." [Tradução livre]

3 Em agosto de 2005, ocorreu em Israel o "Plano de desengajamento" que previu a retirada dos colonos israelenses da Faixa de Gaza.
} 
VIEIRA, José Rodolfo. Footnotes in Gaza: representações sobre o Hamas durante as eleições na Palestina por meio das histórias em quadrinhos de Joe Sacco. Domínios da imagem, v. 13, n. 24, p. 157-186, jan./jun. 2019.

eleições pudessem ocorrer, ou seja, a participação do Hamas no pleito eleitoral:

\begin{abstract}
As eleições do Conselho Legislativo Palestino de 2006 enfrentam um desafio único, pois incluem a participação de um grupo, o Movimento de Resistência Islâmica, ou Hamas, que defende a violência (incluindo o assassinato de civis) como meio de alcançar um fim político, se recusa a desistir das armas ou declarar um cessar-fogo permanente e está comprometido com a destruição de um estado membro das Nações Unidas, Israel. Embora seja do interesse de longo prazo do desenvolvimento democrático palestino e provavelmente nos interesses de segurança de longo prazo de Israel que um amplo espectro de grupos participe de processos políticos lícitos e pacíficos, a atual participação política do Hamas, enquanto simultaneamente defende a violência, princípio das eleições democráticas 4 (UNITED NATIONS, 2006a).
\end{abstract}

Poucos dias após a apresentação dessa pesquisa nas Nações Unidas, os Estados Unidos passaram a endossar a sua retórica de refutar a participação ao Hamas para concorrer o pleito eleitoral palestino em 2006. Nessa conjuntura, Rice reforça a importância do processo eleitoral na Palestina, mas ressalta a possível exclusão do Hamas das eleições, nas palavras de Rice:

\footnotetext{
4 [No original]: "The 2006 Palestinian Legislative Council elections face a unique challenge in that they include the participation of a group, the Islamic Resistance Movement, or Hamas, that defends violence (including the killing of civilians) as a means to achieving a political end, refuses to give up arms or to declare a permanent ceasefire and is committed to the destruction of a United Nations member state, Israel. While it is in the long term interest of Palestinian democratic development and likely in the long term security interests of Israel that a wide spectrum of groups participate in lawful and peaceful political processes, Hamas' current political participation, while simultaneously advocating violence, undermines a fundamental principle of democratic elections." [Tradução livre].
} 
VIEIRA, José Rodolfo. Footnotes in Gaza: representações sobre o Hamas durante as eleições na Palestina por meio das histórias em quadrinhos de Joe Sacco. Domínios da imagem, v. 13, n. 24, p. 157-186, jan./jun. 2019.

A realização de eleições livres e justas do Conselho Legislativo Palestino em 25 de janeiro representa um passo fundamental no processo de construção de um Estado Palestino pacífico e democrático. O Quarteto já afirmou anteriormente que os grupos armados não têm lugar no processo democrático. Continua a ser a opinião dos Estados Unidos de que não deve haver lugar no processo político para grupos ou indivíduos que se recusem a renunciar ao terror e à violência, reconheçam o direito de Israel existir e desarmar ${ }^{5}$ (UNITED NATIONS, 2006a).

A insatisfação estadunidense em relação à participação do Hamas nas eleições não impediu que Steven Erlanger, colunista do The New York Times, publicasse dois dias antes (23 de janeiro de 2006) das eleições na Palestina uma matéria que discorria sobre a ajuda financeira realizada pelos Estados Unidos, desde agosto de 2005, para fortalecer as candidaturas do Fatah, maior concorrente do Hamas pelas cadeiras no corpo legislativo. Como descreveu Erlanger para o The New York Times:

\begin{abstract}
Autoridades americanas e palestinas que falaram anonimamente porque não estavam autorizadas a falar com repórteres disseram que o programa, que começou em agosto, deveria ajudar a derrotar o Hamas e que o governo fez uma análise política detalhada para tentar se concentrar nos distritos eleitorais. O Escritório de Iniciativas de Transição da agência de desenvolvimento internacional recebeu até US \$30.000 em gastos discricionários para cada projeto, em vez dos US \$10.000 normalmente alocados6 (ERLANGER, 2006).
\end{abstract}

\footnotetext{
${ }^{5}$ [No original] "Holding free and fair Palestinian Legislative Council elections on January 25 represents a key step in the process of building a peaceful, democratic Palestinian state. The Quartet has previously stated its view that armed groups have no place in the democratic process. It remains the view of the United States that there should be no place in the political process for groups or individuals who refuse to renounce terror and violence, recognize Israel's right to exist, and disarm" [Tradução livre].

6 [No original] "American and Palestinian officials who spoke anonymously because they were not authorized to speak to reporters said that the program, which started in August, was intended to help defeat Hamas and that the government had done a detailed political analysis to try to focus on constituencies where Hamas was doing well. The international development agency's Office of Transition Initiatives was allowed as much as $\$ 30,000$ in discretionary spending for each project instead of the \$10,000 usually allotted." [Tradução livre].
} 
VIEIRA, José Rodolfo. Footnotes in Gaza: representações sobre o Hamas durante as eleições na Palestina por meio das histórias em quadrinhos de Joe Sacco. Domínios da imagem, v. 13, n. 24, p. 157-186, jan./jun. 2019.

Scott Wilson e Glenn Kessler também noticiaram para o The Washington Post o programa de financiamento estadunidense para projetos na Palestina antes das eleições. Tal como noticiado por Erlanger, Wilson e Kessler afirmam que os projetos tinham como intuito fortalecer a imagem do Fatah na Faixa de Gaza. Conforme os enviados:

O programa de aproximadamente US \$ 2 milhões está sendo liderado por uma divisão da Agência dos EUA para o Desenvolvimento Internacional. Mas nenhum logotipo do governo dos EUA aparece com os projetos ou eventos que estão sendo realizados como parte da campanha, o que não evidencia o envolvimento dos EUA e não se enquadra nas definições do trabalho tradicional de desenvolvimento ${ }^{7}$ (WILSON; KESSLER, 2006).

Como pudemos verificar, não era do interesse dos Estados Unidos, e nem de Israel, que o Hamas conseguisse a maioria das cadeiras no corpo legislativo palestino. Com a vitória surpreendente conquistada pelo Hamas, o então presidente dos Estados Unidos, George W. Bush reafirmou que não negociaria com a Palestina enquanto o Hamas não renunciasse a prática do terrorismo e da violência. Conforme relatado por Steven Erlanger e Greg Myre para o The New York Times em 27 de janeiro de 2006, logo após a confirmação da vitória do Hamas na Palestina:

\footnotetext{
7 [No original] "The approximately $\$ 2$ million program is being led by a division of the U.S. Agency for International Development. But no U.S. government logos appear with the projects or events being undertaken as part of the campaign, which bears no evidence of U.S. involvement and does not fall within the definitions of traditional development work." [Tradução livre].
} 
VIEIRA, José Rodolfo. Footnotes in Gaza: representações sobre o Hamas durante as eleições na Palestina por meio das histórias em quadrinhos de Joe Sacco. Domínios da imagem, v. 13, n. 24, p. 157-186, jan./jun. 2019.

Israel, os Estados Unidos e a Europa rotulam o Hamas como uma organização terrorista e, enquanto autoridades americanas e européias dizem que não vão se reunir ou lidar com autoridades do Hamas, eles continuarão a ter relações estreitas com Abbas e um novo primeiro-ministro palestino, tanto quanto no Líbano, onde o Hezbollah, um partido radical islâmico, tem representação no gabinete ${ }^{8}$ (ERLANGER; MYRE, 2006).

Essa representação do Hamas como sendo um corpo terrorista também é compartilhada por pesquisadores ou pessoas influentes tanto nos Estados Unidos como fora dele. Por exemplo, o advogado e defensor da causa israelense nos Estados Unidos, Alan Dershowitz, representa o Hamas como sendo um grupo extremamente violento e que não irá parar com suas atrocidades até ver o fim do Estado de Israel:

[...] alguns dos principais grupos terroristas, tais como o Hamas, o Jihad Islâmico e o Hezbollah, opõem-se à existência de Israel e rejeitam a criação de um Estado palestino na margem ocidental e em Gaza. Juraram continuar o terrorismo contra os judeus de Israel até que toda Palestina seja libertada e nenhum centímetro dela esteja sob controle judeu. Para eles, a mera contiguidade é irrelevante. Eles querem tudo (DERSHOWITZ, 2004, p. 150).

Nessa concepção disseminada por especialistas como Dershowitz e até mesmo pelo The New York Times, o terrorismo é a ferramenta política de negociação por parte do Hamas. O britânico Bernard Lewis traz a luz o conceito de fedayeen para fazer alusão aos atos violentos cometidos pelo Hamas. Segundo Lewis (2004, p. 140) "O novo tipo de missão suicida, no estrito senso da palavra, parece ter sido introduzido por organizações religiosas como o Hamas e o Hezbollah, que, a partir de 1982, realizaram inúmeras missões desse tipo no Líbano e em Israel". Em sua visão, a prática de tiranicídio executada pelos muçulmanos há mais de mil anos é considerada por ele

\footnotetext{
8 [No original]: "Israel, the United States and Europe all label Hamas a terrorist organization, and while American and European officials say they will not meet or deal with any Hamas officials, they will continue to have close relations with Mr. Abbas and a new Palestinian prime minister, much as they do in Lebanon, where Hezbollah, a radical Islamic party, has cabinet representation." [Tradução livre];
} 
VIEIRA, José Rodolfo. Footnotes in Gaza: representações sobre o Hamas durante as eleições na Palestina por meio das histórias em quadrinhos de Joe Sacco. Domínios da imagem, v. 13, n. 24, p. 157-186, jan./jun. 2019.

como a gênese do terrorismo no Oriente Médio. O Hamas seria então herdeiro direto dessa prática, mas, teria complementado novos elementos em sua maneira de agir.

Por meio dessa visão de mundo, fica claro que a participação do Hamas nas eleições é algo prejudicial para as futuras negociações de paz entre Israel e Palestina. O Hamas é representado como sendo um grupo terrorista e radical, que só tem como objetivo a destruição de Israel. Em 11 de janeiro de 2006, o porta voz da Autoridade Palestina, representando o Fatah, dizia que "A situação está ficando cada vez pior e estamos realmente preocupados com a guerra civil" (THE NEW YORK TIMES, 2006). O medo irracional de uma guerra civil era instaurado caso a vitória do Hamas fosse concretizada. Dessa maneira, o Hamas era o "inimigo" que deveria ser derrotada pelo bem maior da democracia.

Por outro lado, enquanto essas representações eram construídas em torno do Hamas, Joe Sacco produzia "Notas sobre Gaza". Em todas as páginas de seu trabalho Sacco insere a data em que cada página foi produzida. Isso facilita nosso trabalho, pois é possível cruzar os acontecimentos descritos pelos meios de comunicação com o período de produção de cada etapa de "Notas sobre Gaza". Considerando a realização das eleições na Palestina em janeiro de 2006, delimitamos em "Notas sobre Gaza" todo material datado como "01/2006" (janeiro de 2006). Desse recorte da fonte de pesquisa, foi possível averiguar a produção do capítulo intitulado "A resistência e a sulta".

O capítulo começa com Sacco na casa de um amigo de Abed (um palestino que acompanha Sacco durante sua visita na Palestina) em Khan Younis em uma noite em que as Forças de Defesa de Israel (FDI) invadem a aldeia na busca de colaboradores do Hamas ou de outros grupos fundamentalistas. Escondido na casa do amigo de Abed, Sacco conversa com Khaled (um palestino muito conhecido na região e pertencente aos fedayeen e ao Hamas) e todos discutem sobre a superioridade do poder 
VIEIRA, José Rodolfo. Footnotes in Gaza: representações sobre o Hamas durante as eleições na Palestina por meio das histórias em quadrinhos de Joe Sacco. Domínios da imagem, v. 13, n. 24, p. 157-186, jan./jun. 2019.

bélico israelense contra o poder armamentista dos palestinos. Um dos amigos de Abed comenta que "Eles têm todas as vantagens tecnológicas, conseguem ver exatamente no que estão atirando, e ainda assim continuam matando civis" (SACCO, 2010, p. 58). A partir desse momento, Sacco discorre que os palestinos também matam civis, mesmo não dispondo de armas tão sofisticadas quanto aos que os israelenses têm em mãos.

A disparidade da força bélica entre os palestinos, que se consideram como resistência, e as Forças de Defesa de Israel (FDI) é pontuada em muitas passagens de "Notas sobre Gaza". Nesse recorte referente a janeiro de 2006, Sacco não deixou de inserir essa crítica, como podemos observar na imagem 1, que corresponde uma coluna no final da última página do capítulo. No primeiro requadro é possível averiguar a presença de dois soldados da sulta no canto esquerdo inferior do requadro. Ambos os soldados estão sentados fumando seus cigarros, como pode ser visto tanto na mão deles como também pela existência de uma cartela de cigarro em cima de uma mesa. Em cima dessa mesma mesa, há também dois copos de alguma bebida. Em segundo plano, observa-se uma criança que olha para esses soldados sentados. A paisagem é composta por destroços da cidade, possivelmente relacionada com a operação Summer Rains, das FDI. Sobre a operação Summer Rains;

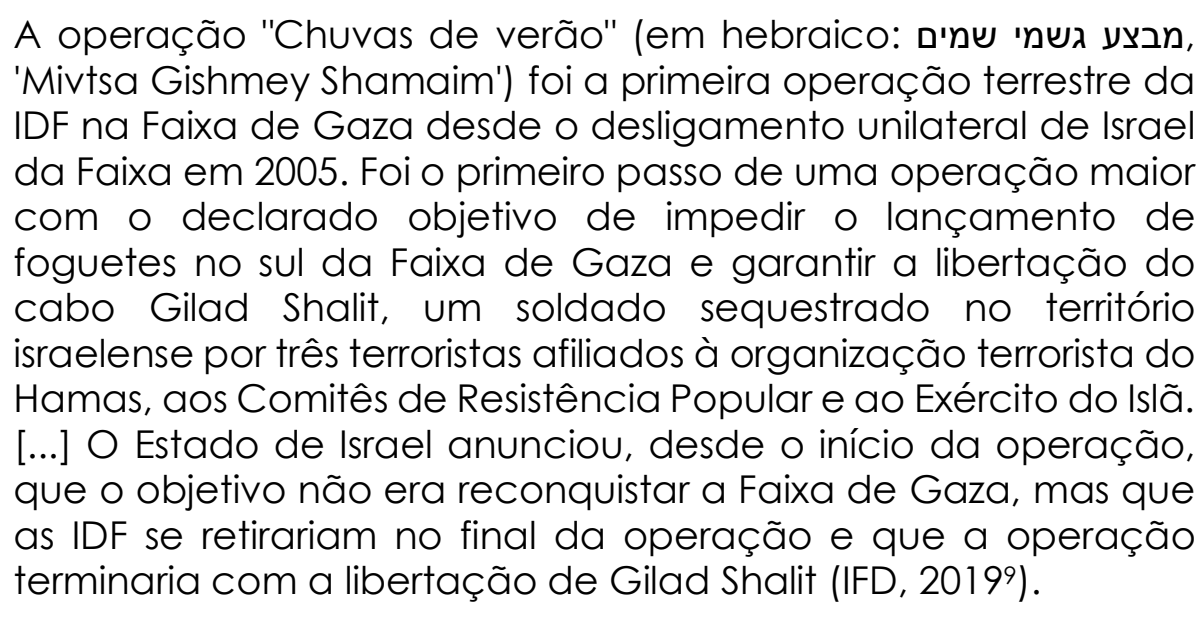

9 [No original]: "The State of Israel announced from the beginning of the operation that the goal was not to reconquer the Gaza Strip, but rather that the IDF would withdraw at the end 
VIEIRA, José Rodolfo. Footnotes in Gaza: representações sobre o Hamas durante as eleições na Palestina por meio das histórias em quadrinhos de Joe Sacco. Domínios da imagem, v. 13, n. 24, p. 157-186, jan./jun. 2019.

Conforme as informações do portal da FDI, a operação Summer Rains foi a primeira investida contra a Faixa de Gaza após o Plano de Desengajamento, operado em agosto de 2005, que visava a retirada unilateral dos colonos israelenses da Faixa de Gaza. O Plano de Desengajamento ficou muito conhecido pela troca de terra por paz, conforme a convicção do então Primeiro Ministro israelense Ariel Sharon. Apesar do objetivo da expedição de resgatar o soldado Gilad Shalit, ocorreu também grande destruição da infraestrutura palestina, como o próprio portal salienta ao discorrer que houve bombardeios por parte de Israel contra alvos específicos do Hamas (IDF, 2019). Portanto, podemos refletir que esse primeiro requadro da imagem 1 representa a incapacidade de os agentes da sulta em defender a população palestina contra as investidas israelenses. Dessa maneira, o garoto que se encontra por detrás dos soldados, observa a impotência daqueles que os deveriam salvaguardar.

\section{Imagem 1 - A sulta, a resistência, o exército de Israel e um menino.}

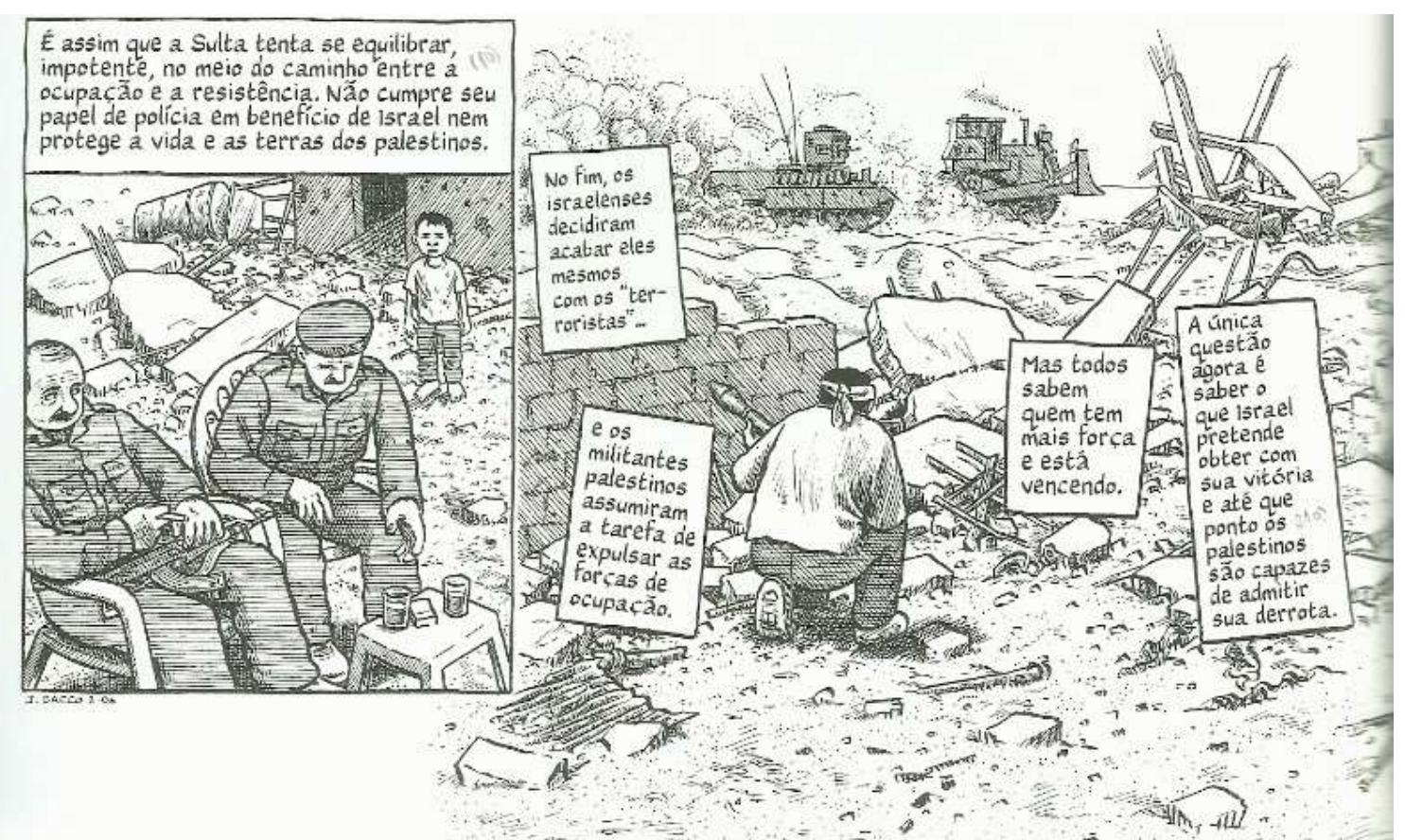

Fonte: SACCO, Joe. Notas sobre Gaza. Tradução: Alexandre Boide. Sã̃o Paulo: Companhia das Letras, 2010. p. 62.

of the operation, and that the operation would end in the release of Gilad Shalit." (Tradução livre), 
VIEIRA, José Rodolfo. Footnotes in Gaza: representações sobre o Hamas durante as eleições na Palestina por meio das histórias em quadrinhos de Joe Sacco. Domínios da imagem, v. 13, n. 24, p. 157-186, jan./jun. 2019.

No requadro ao lado, observamos então a representação de um militante da resistência armada palestina, muito possivelmente um soldado do Hamas. Nesse requadro, examina-se o jovem palestino em primeiro plano, portanto em sua mão um foguete de curto alcance. Por outro lado, em segundo plano é desenhado por Sacco um trator (utilizado para demolir a infraestrutura palestina) e um tanque de guerra israelense que batem em retirada da Faixa de Gaza. Nessa conjuntura, a representação referente à disparidade entre o poderio bélico e as FDI e os militantes do Hamas é exorbitante. Logo, o conjunto desses dois requadros é importante para compreender a impotência por parte da sulta, que seria a responsável legal pelas vidas palestinas, diante dos israelenses durante a operação Summer Rains. Ao mesmo tempo, essa crítica se estende na diferença entre a força de ataque dos israelenses (representado pelo tanque de guerra) e o poder de defesa dos palestinos (representado pelo lançador de foguetes de pequeno alcance).

Outra questão que se desenrola a partir desse pensamento é a de qual parte da resistência palestina cada homem ali dentro participa. Daqui em diante Sacco representa quem é a resistência palestina, e a imagem 2 colabora para que possamos compreender tal resistência. Na imagem é possível verificar cinco homens, sendo que três deles estão utilizando armamento e vestimentas militares. Desses três homens dois estão encapuzados o que só permite ver seus olhos. Além disso, esses dois homens estão vestindo roupas camufladas, enquanto o terceiro homem, que também é um militar, não utiliza uniforme camuflado e ao invés do capuz veste uma boina. Em várias páginas de "Notas sobre Gaza" são representados homens vestindo uniformes militares, mas o que mais desperta a atenção nesse recorte é que esses uniformes não são representações dos uniformes israelenses, mas sim de homens palestinos vestindo uniforme militar. Os outros dois homens que compõem a imagem são palestinos, possível de verificar por meio do estereótipo construído por Sacco, tal como a vestimenta popular, o nariz 
VIEIRA, José Rodolfo. Footnotes in Gaza: representações sobre o Hamas durante as eleições na Palestina por meio das histórias em quadrinhos de Joe Sacco. Domínios da imagem, v. 13, n. 24, p. 157-186, jan./jun. 2019.

avantajado e a barba. Nesse requadro, Sacco representa três homens palestinos, pertencentes ao Fatah torturando outros homens palestinos para retirar informações a respeito do Hamas e da Jihad Islâmica.

Imagem 2 - Soldados palestinos torturando palestinos.

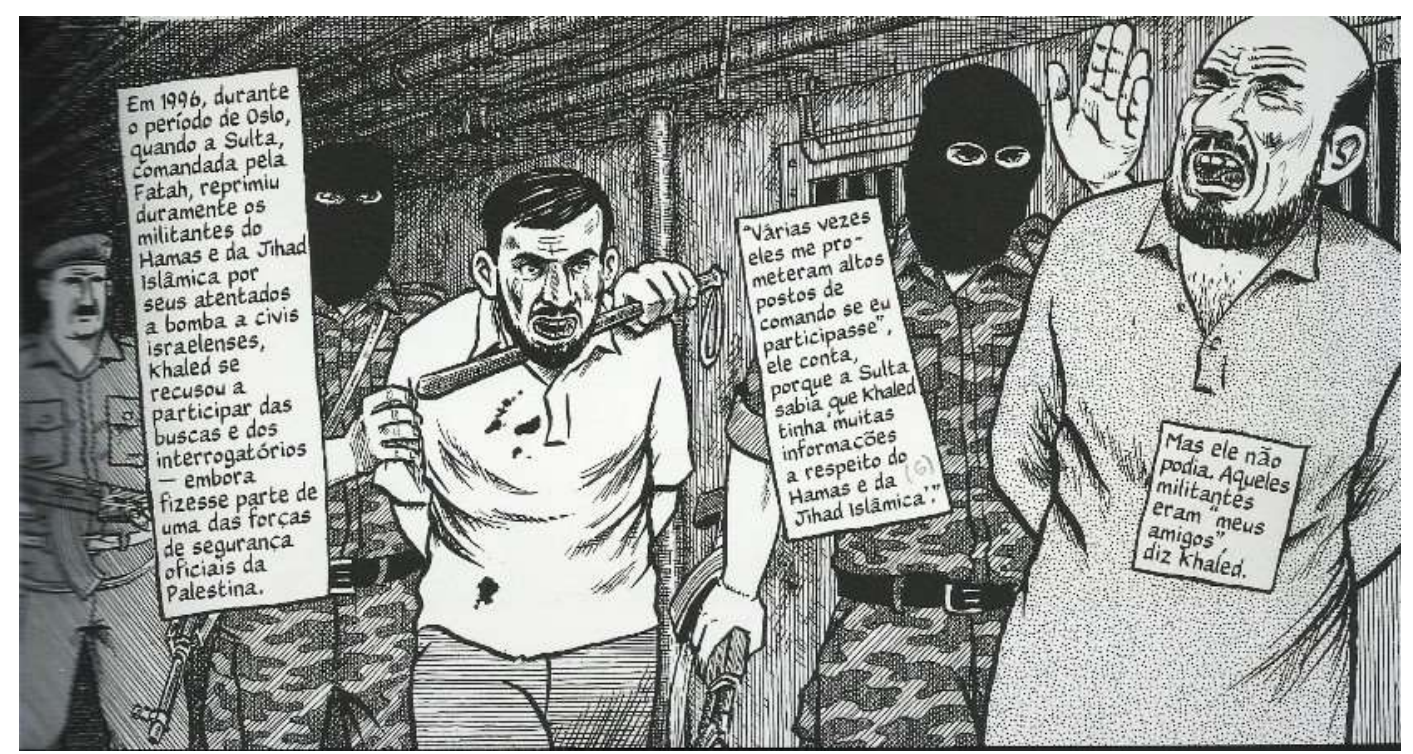

Fonte: SACCO, Joe. Notas sobre Gaza. Tradução: Alexandre Boide. São Paulo: Companhia das Letras, 2010. p. 59.

Na roda de conversa com os amigos de Abed, todos começam a discutir sobre as obrigações que a sulta, o governo palestino instituído na Autoridade Palestina (AP), impõe para homens como Khaled. Atlee, outro combatente e procurado palestino diz que quando se negou a fazer o que a sulta o pedia, tinha como punição o seu salário cortado. Para Atlee, "Todos aqueles altos funcionários da sulta agem em interesse próprio. Aceitaram a presença da Coca-Cola, da Companhia de Gás. Tomam café da manhã em Tel Aviv, jantam em Haifa e vão dançar em Jerusalém. Não tem problema nenhum" (SACCO, 2010, p. 61). Nessa conjunruta, Sacco representa Khaled e Atlee como veteranos de combate que trocaram seus cargos e bons salários nos serviços de segurança da sulta, que em muitos casos os obrigavam torturar seus colegas palestinos. Dessa maneira, esses homens, que fazem parte do Hamas, são representados como sendo a resistência palestina. 
VIEIRA, José Rodolfo. Footnotes in Gaza: representações sobre o Hamas durante as eleições na Palestina por meio das histórias em quadrinhos de Joe Sacco. Domínios da imagem, v. 13, n. 24, p. 157-186, jan./jun. 2019.

Diferentemente das representações do Hamas terrorista e violento descrita nos meios de comunicação, em Notas sobre Gaza os palestinos que são contrários ao governo instituído pela sulta, governo esse que possui alinhamento com os interesses israelenses, são representados como a única resistência da população palestina mais pobre. Esse quadro descrito por Sacco faz alusão a humilhação constante que os palestinos são colocados em seu cotidiano. Não só na caracterização de uma grande humilhação imposta pela ocupação dos territórios e o rígido controle das Forças de Defesa de Israel, mas também de pequenas humilhações. Sobre essas pequenas humilhações, o filósofo Slavoj Zizek discorre:

Passa-se então a perceber uma certa realidade: a realidade de centenas de pequenas - e outras não tão pequenas assim humilhações diárias sistemáticas a que são submetidos os palestinos - os palestinos, e até os árabes israelenses (oficialmente cidadãos de Israel, com todos os direitos de cidadania), são discriminados na alocação de água, nos negócios envolvendo patrimônio, e assim por diante. Mas, ainda mais importante, é a sistemática 'micropolítica' de humilhação psicológica: os palestinos são tratados basicamente como crianças malcriadas que devem ser reeducados para uma vida honesta por meio de disciplina e castigo (ZIZEK, 2003, p. 135).

É nesse conjunto de humilhações diárias sistemáticas que compreendemos o desinteresse da população palestina pelo Fatah e a esperança de resistência na vitória eleitoral do Hamas. Na Faixa de Gaza, local que apoiou maciçamente a candidatura do Hamas ao corpo legislativo, Sacco discorre que:

Principalmente no sul de Gaza, em um lugar como Rafah, por exemplo, o controle da Sulta é quase inexistente. Segundo Atlee: "Eles sabem que podemos virar a cidade de pernas para o ar em poucos minutos e conseguir o apoio da população. Somos respeitados pelo povo" (SACCO, 2010, p. 62). 
VIEIRA, José Rodolfo. Footnotes in Gaza: representações sobre o Hamas durante as eleições na Palestina por meio das histórias em quadrinhos de Joe Sacco. Domínios da imagem, v. 13, n. 24, p. 157-186, jan./jun. 2019.

A sulta e o Fatah são então considerados como corruptos pelo povo palestino representado por Sacco, pois quando Atlee mencionou que a sulta permitiu que a Coca-Cola fosse comercializada na Palestina, além disso, podemos também entender como a aceitação da ajuda financeira estadunidense, reportada por Erlanger, Wilson e Kessler, tanto no The New York Times como no The Washington Post, foi percebida pelos palestinos como uma forma de corrupção por parte do governo vigente nos territórios ocupados.

Em relação às formas de corrupção compreendidas pelos palestinos e ao averiguar as representações de Sacco, produzidas no mesmo período em que essas reportagens foram publicadas, o investimento financeiro por parte dos Estados Unidos para o fortalecimento da campanha do Fatah vai além de melhorias na infraestrutura palestina. Esse dinheiro financia desde a pequena corruptela cultural ao deixar entrar a Coca-Cola nos territórios ocupados como também o financiamento de torturados em busca de "terroristas" do Hamas.

Quando Sacco escreve que "E, ainda que a Sulta - que sofre um (sic) grande pressão de Israel e dos Estados Unidos para eliminar o "terrorismo" que nasce em seu território - tenha apaziguado muitos combatentes veteranos com empregos e cargos nos serviços de segurança [...]" (SACCO, 2010, p. 61) percebe-se que para Sacco a Sulta é uma ferramenta dos Estados Unidos e de Israel para apaziguar e exterminar a resistência do Hamas na Palestina. Isso representa então como o auxílio financeiro estadunidense tem repercutido nos territórios ocupados. Sobre os financiamentos estadunidenses, Fukuyama discorre que:

Existem limites rígidos para atenção do povo americano a assuntos externos e sua disposição para financiar projetos no exterior que não tenham benefícios claros para os interesses dos EUA. Os ataques de 11 de setembro mudaram esse cálculo de muitas maneiras, provendo apoio popular para duas guerras no Oriente Médio e grandes aumentos nos gastos com defesa (FUKUYAMA, 2006, p. 113). 
VIEIRA, José Rodolfo. Footnotes in Gaza: representações sobre o Hamas durante as eleições na Palestina por meio das histórias em quadrinhos de Joe Sacco. Domínios da imagem, v. 13, n. 24, p. 157-186, jan./jun. 2019.

Nesse caso, o objetivo parece muito claro, impedir que o Hamas seja eleito de forma legítima e democrática pelo povo palestino. Como afirma Nederveen (2009, p. 123) os cofres estadunidenses e o FMl após a Guerra Fria tornaram-se um instrumento político para premiar nações amigas ou punir os inimigos dos Estados Unidos. Nesse caso, premia-se o Fatah enquanto pune-se o Hamas. O fato de os Estados Unidos não permitirem que o Hamas participasse das eleições parece um tanto quanto contraditório, visto que poucos anos antes das eleições na Palestina, os Estados Unidos haviam invadido o Afeganistão e o Iraque para a disseminação da democracia. Segundo Hobsbawm:

Estamos atualmente engajados no que pretende ser um reordenamento planejado do mundo, protagonizado pelos países poderosos. As guerras do Iraque e do Afeganistão são apenas uma parte de um esforço supostamente universal de criação de uma nova ordem mundial por meio da 'disseminação da democracia'. Essa ideia não é apenas quixotesca: é perigosa. A retórica que envolve essa cruzada implica que tal sistema é aplicável de forma padronizada (ocidental), que pode ter êxito em todos os lugares, que pode remediar os dilemas transnacionais do presente e que pode trazer a paz, em vez de semear a desordem (HOBSBAWM, 2007, p. 116).

Dessa maneira, a tentativa de barrar o Hamas de participar das eleições faz parte desse novo reordenamento mundial planejado. No Oriente Médio, além das guerras contra o Afeganistão e o Iraque, o conflito palestino, apesar de não ter sido travado diretamente pelos Estados Unidos, estava na rota de colisão dessa "disseminação da democracia". Ao negar a participação do Hamas, nas representações de Sacco, os Estados Unidos também estariam impedindo que a resistência palestina respirasse em uma guerra já perdida, pois como finaliza Sacco "No fim, os israelenses decidiram acabar eles mesmos com os 'terroristas' [...] A única questão agora é saber o que Israel pretende obter com sua vitória e até que ponto os palestinos são capazes de admitir sua derrota" (SACCO, 2010, p. 62). 
VIEIRA, José Rodolfo. Footnotes in Gaza: representações sobre o Hamas durante as eleições na Palestina por meio das histórias em quadrinhos de Joe Sacco. Domínios da imagem, v. 13, n. 24, p. 157-186, jan./jun. 2019.

\section{Considerações Finais}

Após essa análise acerca das eleições para o corpo legislativo palestino em janeiro de 2006, podemos averiguar que não era de interesse dos Estados Unidos a participação do Hamas nas eleições. Essa relutância foi expressa tanto por meio de discursos nas Nações Unidas como pelo financiamento das candidaturas do Fatah para obter a maioria das cadeiras. E respondendo a nossa questão inicial, Notas sobre Gaza apesar de ter como eixo narrativo os massacres nas aldeias de Khan Younis e Rafah, em 1956, possui suas críticas pontuais a política externa estadunidense. E como foi possível observar essas críticas?

A conversa na casa de Khaled, além de representar discursivamente a disparidade bélica entre o exército de Israel e os membros do Hamas, representa também o medo que permeia esses homens pela possível captura por parte das Forças de Defesa de Israel. Além disso, essa conversa desencadeou a discussão sobre a Sulta e a resistência dentro da Palestina. Enquanto os meios de comunicação analisados para esse trabalho - The New York Times e The Washington Post - discorriam em vários momentos sobre os problemas que uma eventual vitória do Hamas poderia ser maléfica para as conversações de paz entre Israel e Palestina. Em outros momentos, também foi apontado que o Hamas não deixaria de ser o braço armado na Palestina. Esse era o quadro desenhado pelos meios de comunicação estadunidenses.

Em contrapartida, a visão de mundo de Joe Sacco representava o Hamas como sendo uma das únicas opções de resistência do povo palestino contra a ocupação israelense. Ao representar Khales e Atlee como desertores da sulta, que preferiram lutar ao lado de seus iguais ao invés de torturá-los em troca de um salário patrocinado indiretamente pelos Estados Unidos, demonstra além de um código de conduta moral não escrito entre os palestinos, o papel que esses homens desempenham na defesa dos mais pobres. 
VIEIRA, José Rodolfo. Footnotes in Gaza: representações sobre o Hamas durante as eleições na Palestina por meio das histórias em quadrinhos de Joe Sacco. Domínios da imagem, v. 13, n. 24, p. 157-186, jan./jun. 2019.

Portanto, existe a disputa pela verdade em um jogo de sistemas de representações, que ambos os grupos visam representar a sua verdade para o público estadunidense. Se de um lado os meios de comunicação favorecem, direta ou indiretamente, a legitimação da agenda neoconservadora e o apoio à causa israelense no Oriente Médio, por outro lado acontece a desconstrução desses símbolos que representam, nesse caso, o Hamas como o inimigo que deve ser combatido, e produzem a humanização do outro.

\section{Referências}

ANDERSON, Perry. A política externa norte-americana e seus teóricos. São Paulo: Boitempo, 2015.

BARKER, Martin. The Reception of Joe Sacco's Palestine. Participations. East Anglia. v.9, n.2. p. 58-73, 2012.

CHARTIER, Roger. A História Cultural: Entre práticas e representações. Rio de Janeiro: Editora Bertrand Brasil, 1990.

CHOMSKY, Noam. Mídia: propaganda política e manipulação. São Paulo: Editora WMF Martins Fontes, 2013.

DERSHOWITZ, Alan. Em defesa de Israel. São Paulo: Nobel, 2004.

ERLANGER, Steven. U.S. Spent \$1.9 Million to Aid Fatah in Palestinian Elections. The New Yotk Times. New York, Archives 23 jan. 2006. Disponível em: https://www.nytimes.com/2006/01/23/world/middleeast/us-spent-19-millionto-aid-fatah-in-palestinianelections.html? mtrref=www.google.com\&gwh $=C 8 F C 7566020 B 4562 D 71$ A637C 77BC1B55\&gwt=pay. Acesso em: 05 maio 2019.

ERLANGER, Steven; MYER, Greg. Hamas Presses Fatah in Palestinian Vote, Surveys Say. The New Yotk Times. New York, Archives, 26 jan. 2006. Disponível em: https://www.nytimes.com/2006/01/26/world/middleeast/hamas-pressesfatah-in-palestinian-vote-surveys-say.html. Acesso em: 12 maio 2019. 
VIEIRA, José Rodolfo. Footnotes in Gaza: representações sobre o Hamas durante as eleições na Palestina por meio das histórias em quadrinhos de Joe Sacco. Domínios da imagem, v. 13, n. 24, p. 157-186, jan./jun. 2019.

FDI. Operations Summer Rains. 2019. Disponível em:

https://www.idf.il/en/minisites/wars-and-operations/operation-summer-rains2006/. Acesso em: 20 out. 2019.

FUKUYAMA, Francis. O dilema americano: democracia, poder e o legado do neoconservadorismo. Rio de Janeiro: Rocco, 2006.

GARCIA, Santiago. A novela gráfica. São Paulo: Martins Fontes, 2012.

GATTAZ, André. A guerra da Palestina: da criação do Estado de Israel à Nova Intifada. São Paulo: Usina do Livro, 2003.

HOBSBAWM, Eric. Globalização, democracia e terrorismo. São Paulo: Companhia das Letras, 2007.

LEWIS, Bernard. A crise do islã: guerra santa e terror profano. Rio de Janeiro: Jorge Zahar Ed., 2004.

MAZUR, Dan; DANNER, Alexander. Quadrinhos: História moderna de uma arte global. Editora WMF Martins Fontes, 2014.

NEDERVEEN PIETERSE, Jan. O fim do império americano?: Os Estados Unidos depois da crise. São Paulo: Geração Editorial, 2009.

SACCO, Joe. Notas sobre Gaza. São Paulo: Companhia das Letras, 2010.

SACCO, Joe. Palestina. São Paulo: Conrad Editora do Brasil, 2011.

STAROBINSKI, Jean. A literatura: o texto e o seu intérprete. In: LE GOFF, J.; NORA, P. História: novas abordagens. Rio de Janeiro: F. Alves, 1976.

UNITED NATIONS. Conclusions on the Middle East peace process - EU General Affairs and External Relations Council meeting - EU press release/Non-UN document. 2005. Disponível em:

https://www.un.org/unispal/document/conclusions-on-the-middle-eastpeace-process-eu-general-affairs-and-external-relations-council-meeting-eupress-release-non-un-document-3/. Acesso em: 10 fev.2019.

UNITED NATIONS. Pre-election assessment of the PLC elections - Statement of NDI/Carter Center Intl. Observer Delegation - NDI/Carter Center press release/Non-UN document. 2006a. Disponível em:

https://www.un.org/unispal/document/pre-election-assessment-of-the-plcelections-statement-of-ndi-carter-center-intl-observer-delegation-ndi-cartercenter-press-release-non-un-document/. Acesso em: 22 fev. 2019. 
VIEIRA, José Rodolfo. Footnotes in Gaza: representações sobre o Hamas durante as eleições na Palestina por meio das histórias em quadrinhos de Joe Sacco. Domínios da imagem, v. 13, n. 24, p. 157-186, jan./jun. 2019.

UNITED NATIONS. Secretary Rice statement on security and the Palestinian elections - USDOS press release. 2006b. Disponível em:

https://www.un.org/unispal/document/secretary-rice-statement-on-securityand-the-palestinian-elections-usdos-press-release/. Acesso em: 05 abr. 2019.

UPPSALA UNIVERSITY. Ucdp. 2019. Disponível em:

https://ucdp.uu.se/\#country/666. Acesso em: 10 jun. 2019.

WILLIS, Susan. Evidências do Real: Os Estados Unidos pós-11 de Setembro. São Paulo: Boitempo, 2008.

WILSON, Scott; KESSLER, Glenn. U.S. Funds Enter Fray In Palestinian Elections Bush Administration Uses USAID as Invisible Conduit. The Washington Post. Washington, 22 jan. 2006. Disponível em:

https://www.washingtonpost.com/archive/politics/2006/01/22/us-funds-enterfray-in-palestinian-elections-span-classbankheadbush-administration-usesusaid-as-invisible-conduitspan/3342f760-09d3-400e-93902c5d6f51f442/?utm_term=.6dec733489db. Acesso em: 12 maio 2019.

ZIZEK, Slajov. Bem-vindo ao deserto do Real!: cinco ensaios sobre o 11 de Setembro e datas relacionadas. São Paulo: Boitempo Editorial, 2003. 